\title{
IDH1 mutation analysis - an example of putative glioma marker
}

\author{
Marzena Lewandowska ${ }^{1,6^{*}}$, T Szylberg ${ }^{2}$, K Roszkowski $^{3}$, J Furtak ${ }^{4}$, W Windorbska ${ }^{5}$, J Rytlewska', W Jóźwicki ${ }^{1,7}$ \\ From Annual Conference on Hereditary Cancers 2011 \\ Szczecin, Poland. 17-18 November 2011
}

The astrocytoma cancer represents CNS neoplasms in which the predominant cell type is derived from an immortalized astrocyte. The genomewide analysis of glioma identified somatic mutation at codon 132 of the IDH1 gene which encodes NADP+ dependent isocitrate dehydrogenase. Further studies indicated that patients with somatic, heterozygous $\mathrm{R} 132 \mathrm{H}$ mutation have distinct clinical characteristic: younger age at astrocytoma diagnosis (WHO II and WHO III) and improved clinical prognosis. Location of the majority of point mutations in the IDH1 gene are localized at 132 codon - what simplifies the use of this mutation for potential diagnostic purposes.

The presence of R132H IDH1 mutation was analysed in group of 38 patients diagnosed with: fibrillar astrocytoma, astrocytoma gemistocyticum, astrocytoma pilocyticum and astrocytoma anaplasticum. The IDH1 mutation status was determinated by immunohistochemistry using monoclonal antibody specific for the $\mathrm{R} 132 \mathrm{H}$ mutation. Additional data verification was performed by HRM Cold-PCR and Sanger sequencing. For statistical evaluation we distinguished two subgroups of patients: with and without IDH1 R132H mutation. Presence of IDH1 mutation in Polish astrocytomas' patients correlates with better clinical outcome and longer median overall survival. Our findings confirm overall tendency for better survival benefits in patients with IDH1 mutated tumors and indicates that presence or absence of IDH1 mutant proteins may become a potential target in personalized medicine.

\footnotetext{
* Correspondence: lewandowskam@co.bydgoszcz.pl 'Department of Tumor Pathology and Pathomorphology of the Franciszek Lukaszczyk Oncology Center, Bydgoszcz, Poland

Full list of author information is available at the end of the article
}

\section{Author details}

'Department of Tumor Pathology and Pathomorphology of the Franciszek Lukaszczyk Oncology Center, Bydgoszcz, Poland. ${ }^{2}$ Department of Pathomorphology, Military Clinical Hospital, Bydgoszcz, Poland. ${ }^{3}$ Department of Radiotherapy, The Franciszek Lukaszczyk Oncology Center, Bydgoszcz, Poland. ${ }^{4}$ Department of Neurosurgery, Military Clinical Hospital, Bydgoszcz, Poland. ${ }^{5}$ Department of Teleradiotherapy, The Franciszek Lukaszczyk Oncology Center, Bydgoszcz, Poland. ${ }^{6}$ Department of Thoracic Surgery and Tumors, The Ludwik Rydygier Collegium Medicum, Nicolaus Copernicus University, Bydgoszcz, Poland. ${ }^{7}$ Department of Tumor Pathology and Pathomorphology, The Ludwik Rydygier Collegium Medicum, Nicolaus Copernicus University, Bydgoszcz, Poland.

Published: 20 April 2012

\section{doi:10.1186/1897-4287-10-S3-A14}

Cite this article as: Lewandowska et al.: IDH1 mutation analysis - an example of putative glioma marker. Hereditary Cancer in Clinical Practice 2012 10(Suppl 3):A14.
Submit your next manuscript to BioMed Central and take full advantage of:

- Convenient online submission

- Thorough peer review

- No space constraints or color figure charges

- Immediate publication on acceptance

- Inclusion in PubMed, CAS, Scopus and Google Scholar

- Research which is freely available for redistribution
() Biomed Central
C Biomed Central

(c) 2012 Lewandowska et al; licensee BioMed Central Ltd. This is an Open Access article distributed under the terms of the Creative Commons Attribution License (http://creativecommons.org/licenses/by/2.0), which permits unrestricted use, distribution, and reproduction in any medium, provided the original work is properly cited. 